\title{
Pathophysiology and Management of Alcoholic Liver Disease: Update 2016
}

\author{
Felix Stickel ${ }^{1}$, Christian Datz ${ }^{2}$, Jochen Hampe ${ }^{3}$, and Ramon Bataller ${ }^{4}$ \\ ${ }^{1}$ Department of Gastroenterology and Hepatology, University Hospital Zurich, Zurich, Switzerland, ${ }^{2}$ Department of Internal Medicine, Hospital \\ Oberndorf, Teaching Hospital of the Paracelsus Private University of Salzburg, Oberndorf, Austria, ${ }^{3}$ Medical Department 1, University Hospital \\ Dresden, TU Dresden, Dresden, Germany, and ${ }^{4}$ Division of Gastroenterology and Hepatology, Department of Medicine and Nutrition, University \\ of North Carolina at Chapel Hill, Chapel Hill, NC, USA
}

Alcoholic liver disease (ALD) is a leading cause of cirrhosis, liver cancer, and acute and chronic liver failure and as such causes significant morbidity and mortality. While alcohol consumption is slightly decreasing in several European countries, it is rising in others and remains high in many countries around the world. The pathophysiology of ALD is still incompletely understood but relates largely to the direct toxic effects of alcohol and its main intermediate, acetaldehyde. Recently, novel putative mechanisms have been identified in systematic scans covering the entire human genome and raise new hypotheses on previously unknown pathways. The latter also identify host genetic risk factors for significant liver injury, which may help design prognostic risk scores. The diagnosis of ALD is relatively easy with a panel of well-evaluated tests and only rarely requires a liver biopsy. Treatment of ALD is difficult and grounded in abstinence as the pivotal therapeutic goal; once cirrhosis is established, treatment largely resembles that of other etiologies of advanced liver damage. Liver transplantation is a sound option for carefully selected patients with cirrhosis and alcoholic hepatitis because relapse rates are low and prognosis is comparable to other etiologies. Still, many countries are restrictive in allocating donor livers for ALD patients. Overall, few therapeutic options exist for severe ALD. However, there is good evidence of benefit for only corticosteroids in severe alcoholic hepatitis, while most other efforts are of limited efficacy. Considering the immense burden of ALD worldwide, efforts of medical professionals and industry partners to develop targeted therapies in ALF has been disappointingly low. (Gut Liver 2017;11:173-188)

Key Words: Hepatitis, alcoholic; Corticosteroid therapy; Carcinoma, hepatocellular; Liver transplantation; Malnutrition;
PNPLA3

\section{INTRODUCTION}

Alcohol consumption accounts for approximately 3.8\% of all global deaths and 4.6\% of global disability-adjusted life-years. ${ }^{1}$ In Europe, this problem seems to be particularly relevant, with $6.5 \%$ of all deaths attributable to alcohol, ${ }^{2}$ and recent estimates indicate that harmful drinking, particularly when associated with alcohol dependence, is responsible for one in seven deaths in men and one in 13 deaths in women aged 15 to 64 years. ${ }^{3}$ Alcohol use disorders (AUD) are the most frequent cause of liver cirrhosis in Europe, and alcoholic liver disease (ALD) the most important cause of death due to alcohol in adults. ${ }^{4}$ Liver cirrhosis mortality over the past 30 years declined in most Western European countries, while it increased in several Eastern European countries, as well as in the United Kingdom, Ireland, and Finland. ${ }^{5}$ Of note, the all-cause mortality of middle-aged white non-Hispanic men and women in the United States between 1999 and 2013 increased significantly, largely to increasing death rates from drug and alcohol poisonings, chronic liver diseases and cirrhosis. ${ }^{6}$ A strong determinant for alcohol-related organ damage in many-but not all-patients is the alcohol dependence syndrome, a common behavioral disorder characterized by tolerance to the psychotropic effects of alcohol consumption, a preoccupation with alcohol and persistent drinking despite its harmful consequences. Chronic and episodes of binge alcohol abuse also contribute to the development of various somatic and psychiatric disorders and injuries, as well as to several diseases which are predominantly or entirely attributable to alcohol, such as alcohol-induced pancreatitis ${ }^{7}$ and the fetal alcohol syndrome. ${ }^{8}$ Furthermore, alcohol is also a contributory factor to other, diseases and injuries. Among the most impor-

Correspondence to: Felix Stickel

Department of Gastroenterology and Hepatology, University Hospital Zurich, Rämistrasse 100, CH-8091 Zürich, Switzerland

Tel: +41-31-338-7817, Fax: +41-31-335-3519, E-mail: Felix.stickel@uzh.ch

Received on September 23, 2016. Accepted on October 14, 2016. Published online February 21, 2017

pISSN 1976-2283 eISSN 2005-1212 https://doi.org/10.5009/gnl16477

@) This is an Open Access article distributed under the terms of the Creative Commons Attribution Non-Commercial License (http://creativecommons.org/licenses/by-nc/4.0) which permits unrestricted non-commercial use, distribution, and reproduction in any medium, provided the original work is properly cited. 
tant disease conditions affected by alcohol consumption are cancers of the oropharynx, esophagus, liver, colon, rectum and the female breast $;{ }^{9}$ cardiovascular diseases $;{ }^{10}$ neuropsychiatric disorders (epilepsy, depressive disorders) ${ }^{11}$ a (not necessarily complete) summary of physical and mental diseases related to alcohol consumption is given in Table 1 .

\section{EPIDEMIOLOGY AND BURDEN OF DISEASE}

AUD contributes to a large proportion of deaths from liver diseases, either by causing genuine ALD or as a cofactor in patients with non-ALDs such as chronic viral hepatitis, hemochromatosis and fatty liver due to nonalcoholic causes. The Global Burden of Disease Study reported a steadily increasing mortality due to liver diseases with approximately 1 million deaths in 2010 , which is roughly $2 \%$ of the global total mortality. ${ }^{12}$ With this, liver-related years of liver lost (YYL) outscore that of YYL due to cancers of the respiratory tract, esophagus, stomach, colorectum and pancreas together. ${ }^{13}$ To what proportion alcohol consumption contributes to this burden, is not entirely clear since the underlying etiologies of liver disease are not gaplessly recorded in most countries, with great variation across Europe. The most precise figures can be obtained from Finland where $87 \%$ of death cases due to liver disease seem to be alcohol-related. Taking into account the variability across Europe and figures extracted from the World Health Organization (WHO) mortality database, ${ }^{14}$ one can estimate for the European Union that $60 \%$ to $80 \%$ of liver-related mortality is due to excessive drinking. ${ }^{15}$ According to WHO, morbidity attributable to alcohol in developed countries accounts for 10.3\% of disability adjusted life years and comes second only to that of tobacco (11.7\%). Within this figure, liver cirrhosis is responsible for $70 \%$ to $80 \%$ of the directly recorded mortality from alcohol. In 2010, alcoholic liver cirrhosis was responsible for 493,300 deaths (47.9\% of all liver cirrhosis deaths), representing $0.9 \%$ of all deaths regardless the cause $(0.7 \%$ of all deaths of women and $1.2 \%$ of all deaths of men), and 80,600 deaths (14,800 deaths of women and 65,900 deaths of men) were attributable to alcohol-related liver cancer. ${ }^{4}$ Apart from mere mortality figures, harmful alcohol consumption is the second most common indication for liver transplantation, accounting for approximately $40 \%$ of all primary liver transplants in Europe and about 25\% in the United States. ${ }^{16}$ Besides its remarkable health impact, this huge disease burden has an economic impact of about 125 billion Euros annually in Europe, accounting for $1.3 \%$ of the gross domestic product. ${ }^{17}$

\section{SPECTRUM AND PATHOPHYSIOLOGY OF ALD}

Above a certain quantity, alcoholic consumption can elicit a spectrum of liver lesions among which steatosis is present in nearly all drinkers who consume in excess of $40 \mathrm{~g} /$ day regularly. Beyond fatty liver, ALD comprises a continuum of partly

Table 1. Alcohol-Associated Somatic and Mental Diseases

\begin{tabular}{|c|c|}
\hline Acute intoxication (apnea, aspiration of gastric content) & Alcoholic myopathy \\
\hline Alcohol use disorders & Alcoholic osteopathy \\
\hline Gastrointestinal tract, pancreas and liver & Neurological and psychiatric disorders \\
\hline - Alcoholic liver disease & - Peripheral neuropathy \\
\hline - Alcoholic pancreatitis & - Dementia \\
\hline - Cancer of the upper digestive tract (oral cavity, pharynx, & - Cerebellar atrophy with dyskinesia \\
\hline hypopharynx, pharynx, esophagus) & • Depression (including suicide) \\
\hline - Motility disorders (esophagus, gastroesophageal reflux, gastric emptying, diarrhea) & Trauma \\
\hline - Mucosal damage (including hemorrhagic gastritis) & - Bone fractures \\
\hline - Lactose intolerance & - Subdural hematoma \\
\hline - Colorectal cancer & Breast cancer \\
\hline Metabolic disorders & Infections \\
\hline • Hypoglycemia & - Endocarditis \\
\hline • Hyperlipoproteinemia & - Viral hepatitis \\
\hline - Hyperuricemia (including gout) & - Sepsis \\
\hline - Porphyria & - Tuberculosis \\
\hline - Hyperferritinemia & Skin disease \\
\hline Fetal alcohol syndrome & - Psoriasis \\
\hline Cardiovascular disease & - Teleangiectasias \\
\hline - Cardiomyopathy & - Spider angiomas \\
\hline - Arrhythmia (including atrial fibrillation) & - Rhinophyma \\
\hline - Arterial hypertension & - Palmar erythema \\
\hline
\end{tabular}


overlapping liver abnormalities with variable degrees of inflammation and progressive fibrosis in $10 \%$ to $35 \%$ of alcoholics, and liver cirrhosis in approximately $10 \%$ to $15 \%$ of heavy drinkers (Fig. 1). ${ }^{18}$ A great concern is the rising incidence of hepatocellular carcinoma (HCC) which evolves in approximately $1 \%$ to $2 \%$ of alcoholic cirrhotics per year. ${ }^{19}$ While steatosis and inflammation are reversible upon abstinence, and probably also fibrosis below the level of cirrhotic transformation, severe alcoholic steatohepatitis (ASH), decompensating cirrhosis and HCC have a grave prognosis.

The cellular and molecular mechanisms of ALD pathogenesis are still incompletely understood but seem to be related to a complex interaction between behavioral, environmental and genetic factors. The histological hallmarks of ALD, steatosis, inflammation and fibrosis are the result of interrelated and consecutive pathophysiological events in the context of continuous alcohol exposure. A pivotal component in the evolution of ALD is the direct toxicity of the first metabolite of alcohol degradation, acetaldehyde (AA). ${ }^{20}$ Two major enzyme systems can metabolize alcohol to AA via oxidative degradation, of which alcohol-dehydrogenase is the system primarily responsible for the processing of lower amounts of alcohol. It is located in the cytosol and cannot be upregulated upon demand. In contrast, cytochrome P450 2E1 (CYP2E1) located in microsomes is inducible and can be upregulated 10- to 20-fold in heavy drinkers. ${ }^{21}$ Both enzyme systems generate AA, a highly reactive toxic and mutagenic metabolite, by which they not only degrade ethanol (and other organic substances), but also contribute to alcoholrelated toxicity (Fig. 2). Apart from generating AA, CYP2E1 also contributes of oxidative damage by the formation of reactive oxygen species (ROS) such as superoxide anion and hydrogen peroxide. Hepatic CYP2E1 activity in humans may already in-

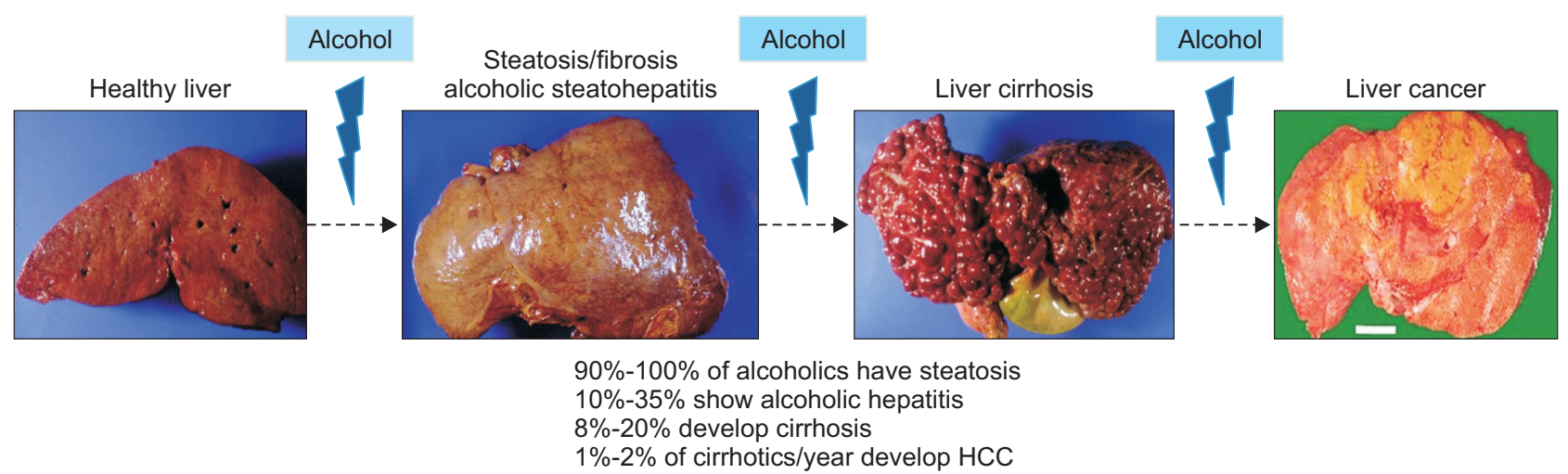

Fig. 1. The progression for alcoholic liver injury to steatosis with scarring, inflammation and architectural distortion leading to cirrhosis. As a complication of cirrhosis, hepatocellular carcinoma may occur. However, only a minority of patients with alcoholic steatosis progress to severe liver injury.

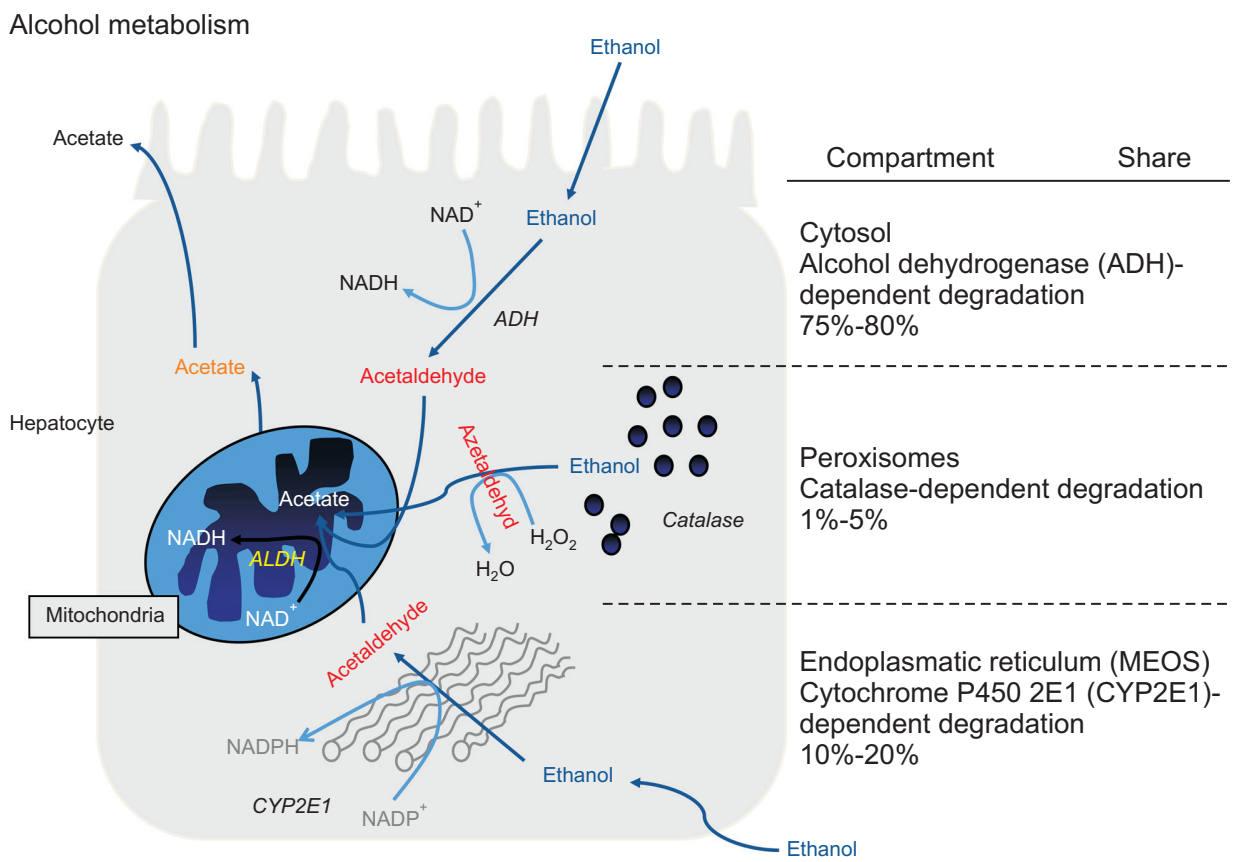

Fig. 2. Hepatic metabolism of ethanol by enzymes ADH, CYP2E1 and catalase. Each enzyme generates acetaldehyde, a toxic and mutagenic metabolite of ethanol. While ADH is metabolically stable regardless of the alcohol challenge and catalase is irrelevant with respect to its role in hepatic alcohol degradation, CYP2E1 is inducible and contributes most to acetaldehyde production during heavy alcohol consumption. 
crease following the ingestion of only $40 \mathrm{~g}$ of ethanol/day for 1 week. $^{22}$ In rodents, the induction of CYP2E1 correlated with NAD phosphate oxidase activity, the generation of hydroxyethyl radicals, lipid peroxidation and the severity of hepatic damage, all of which could be prevented by the CYP2E1 inhibitor clomethiazole. ${ }^{23,24}$ Importantly, AA is also a powerful carcinogen in experimental animals and in humans, and considered an important reason for the association of certain cancers with alcohol consumption. ${ }^{25}$

The initial liver lesion in alcoholics is steatosis which occurs in literally all heavy drinkers as a result of disrupted lipid turnover. ${ }^{26}$ Above all, decreased fatty acid oxidation, increased fatty acid and triglyceride synthesis, increased fat entry into the liver by fatty acid mobilisation from peripheral fat stores and via chylomicrons from the intestine are instrumental. Furthermore, increased lipogenesis by dysregulation of steatogenic enzymes and transcription factors including sterol regulatorybinding protein $1 \mathrm{c}$, peroxisome proliferator-activated receptor $\alpha$, and microsomal triglyceride transport protein are involved. A more recent revelation is the potential role of protein enzymes involved in lipid processing such as PNPLA3 and TM6SF2 for which genetic variants of the coding genes were found associated with ALD (see below). Whether and how alcohol consumption affects the function of these enzymes, however, is still unclear.

Similar to non-ASH, inflammation can occur as an important feature in alcoholic steatosis resulting in ASH, and evolve as a major driving force for fibrogenesis leading to fibrosis, cirrhosis and most likely, hepatocarcinogenesis. Histologically, ASH is characterized by variable degrees of steatosis, a typical inflammatory infiltrate consisting of predominantly polymorphonuclear (PMN) cells, centrilobular hepatocyte ballooning, Mallory-Denk inclusion bodies, and a "chicken wire"-like fibrosis network. ${ }^{27}$ A key pathogenic pathway in this stage is the gutliver axis. Thus, alcohol ingestion increases gut permeability and promotes the translocation of endotoxins from Gram negative bacteria such as lipopolysaccharides (LPS) into the portal bloodstream to reach Kupffer cells which, upon binding of LPS to the endotoxin receptor CD14 activate the MyD88-independent signaling pathway through TLR4, with consecutive production of proinflammatory cytokines such as tumor necrosis factor $\alpha$ that contribute to hepatocellular damage. ${ }^{28-30}$ Additional cytokines and chemokines involved in the activation/recruitment of inflammatory and mesenchymal cells contributing to inflammation and fibrotic repair processes in ALD are interleukin (IL)1, IL-8, and IL-17, osteopontin, chemokine (CXCL)1, CXCL4, CXCL5, and CXCL6. ${ }^{30-32}$ These proinflammatory sequelae are particular prominent in patients with ASH.

The key lesion in chronic liver disease is fibrosis that, in essence, resembles the process of excessive wound healing as a result of increased fibrogenesis and decreased fibrolysis. In progressive fibrosis, liver parenchyma is replaced by excess extra- cellular matrix produced by activated hepatic stellate cells (HSC) and myofibroblasts (MFB), resulting in a distorted liver architecture and progressive functional impairment. ${ }^{33}$ Various triggers can activate liver macrophages (Kupffer cells) and other inflammatory cells which leads to the production of the profibrogenic cytokines platelet-derived growth factor and transforming growth factor- $\beta 1$ which can stimulate HSC/MFB to produce collagens, noncollagenous glycoproteins, proteoglycans, and glycosaminoglycans up to 10-fold compared to normal liver tissue. Here, the fibril forming collagens type I and III make up for $>80 \%$ of total liver collagen. In turn, matrix-degrading enzymes termed matrix-metalloproteinases are downregulated by their corresponding tissue inhibitors. ${ }^{33}$ In ALD, HSCs/MFBs can be stimulated by $\mathrm{AA},{ }^{34} \mathrm{ROS}^{35}{ }^{3}$ leptin, ${ }^{36}$ endocannabinoids ${ }^{37}$ and lipid peroxides. ${ }^{38}$

The most worrisome complication of ALD is HCC, and the vast majority of HCCs develops on the background of alcoholic cirrhosis. $^{39}$ Besides cirrhotic transformation as a precancerous condition, a number of pathophysiological aspects are specific to alcohol-associated HCC. An important trigger of tumor development is $\mathrm{AA}$, which is not only a toxin, but also a highly reactive mutagen that forms stable DNA adducts, causes point mutation, sister chromatid exchanges, inhibits DNA repair, and via induced CYP2E1, activates pro-carcinogens to carcinogens. ${ }^{9}$ Other molecular mechanisms include epigenetic modifications from alcohol by altering DNA methylation. Indeed, epigenetic silencing of hypermethylated tumor suppressor genes and activation of oncogenes via hypomethylation correlate with survival in human HCC including patients with alcoholic cirrhosis. ${ }^{40}$

Recent studies have shed some light on the pathogenesis of ASH. Here, failure of the liver to regenerate the hepatocellular mass seems to play a major role. Explants from ASH patients that underwent liver transplantation revealed that nonresponders to medical therapy had reduced hepatic expression of liver regeneration-related cytokines and the lack of proliferative hepatocytes. ${ }^{41}$ This observation was further confirmed by others, which showed that presence of proliferating hepatocytes in alcoholic hepatitis (AH) is associated with a better prognosis. ${ }^{42}$ In addition, a massive expansion of liver progenitor cells (LPCs) called "ductular reaction" is often observed in AH patients, but these LPCs fail to differentiate into mature hepatocytes and correlate positively with severity of liver disease and short-term mortality in these patients. ${ }^{43}$

\section{Experimental ALD}

Studying ALD experimentally has been extremely difficult since no animal model exists that closely mirrors all relevant features of severe ALD in humans or only pivotal elements of it. $^{44}$ Rodents are notoriously resistant to the hepatotoxic effects of alcohol due to species-related differences in alcohol metabolism, and rats or mice only develop significant chronic liver injury when exposed to alcohol in combination with a second 
toxin (e.g., carbon tetrachloride and thioacetamide) or major dietary manipulations (e.g., choline/methionine deficiency) that still do not produce a histological picture that fully models that of human ALD. ${ }^{45}$ The experimental setup that produces liver lesions most similar to those in humans is the intragastric feeding model, or Tsukamoto-French model in which continuous infusion of alcohol-containing food via a surgically-implanted gastric tube results in typical alcohol-induced liver injury including steatohepatitis, fibrosis and microscopic lesions such as ballooning, Mallory-Denk bodies and neutrophilic inflammatory infiltration. ${ }^{46}$ The lack of a suitable animal model has been a significant impediment to more deeply study ALD experimentally, and is one of the reasons for the suboptimal research on novel biomarkers retrieved from human omics studies (vide infra). Recent advances, such as the National Institute on Alcohol Abuse and Alcoholism model of ALD, that combine binge drinking patterns with chronic alcohol exposure may pave the way for more suitable models. ${ }^{47}$ This can be promising when combined with novel technologies to design genetically modified rodents such as with the CRISPR/Cas9 technique to overcome species-related differences in alcohol susceptibility. ${ }^{48}$

\section{FACTORS MODULATING PROGRESSION OF ALD}

Significant ALD with progressive fibrosis and cirrhosis develops only in a minority of heavy drinkers suggesting that apart from alcohol itself, modifying variables exist that modulate the individual susceptibility to the toxic effects of alcohol. ALD is considered a complex disease in which numerous factors interact to allow for liver disease to occur. These factors are referred to as environmental (exogenous) or host (inherent) disease modifiers which partly explain the large inter-individual variability in the likelihood to develop ALD. Much progress has been made in our understanding of how these factors are entangled as outlined below.

\section{Environmental factors}

The development of ALD requires heavy alcohol drinking, and consensus exists that there is a clear dose-relationship between the amount of alcohol and the likelihood of its development. ${ }^{49,50}$ According to the Dionysos Study from Italy the risk of developing alcoholic cirrhosis is highest in those with a daily consumption of above $120 \mathrm{~g}$ of pure alcohol per day. ${ }^{51}$ Drinking patterns were suggested as modifier of ALD, such as drinking with meals appeared to confer less risk than consuming alcohol outside separately. Regarding the type of alcoholic beverage it was suggested that wine drinking is associated with a lower risk of ALD $;^{52}$ however, scientific persuasion prevails that it is rather the amount of alcohol contained in certain alcoholic beverages than the nonalcoholic contents, and that the effect of different beverages on ALD risk are rather related to lifestyle and dietary factors. ${ }^{53}$ Coffee drinking appears to protect alcohol-related liver injury with people drinking four or more cups a day having one-fifth of the risk of developing cirrhosis as non-coffee drinkers. ${ }^{54}$ In turn, cigarette smoking increases the risk of alcoholic cirrhosis with smokers of $\geq 1$ pack daily showing a 3-fold higher risk than nonsmokers. ${ }^{55}$

Coinfection with viral hepatitis B and C is also recognized as an important promoter of ALD, although the clear distinction between viral hepatitis worsened by alcohol, or vice versa, is often difficult to make and relies mainly on the predominant histology lesion prevalent in a patient with both conditions. The most abundant data exist for the interaction between alcohol and chronic hepatitis $\mathrm{C}$ for which numerous population-based, cross-sectional and cohort studies have demonstrated a higher prevalence of alcohol abuse among hepatitis C virus (HCV)infected subjects, and a higher prevalence of HCV antibodies among drinkers. ${ }^{56}$ In a large study including 800 patients with chronic HCV infection, Monto et al. ${ }^{57}$ showed that those who drink alcohol in excess of $50 \mathrm{~g} /$ day have a significantly higher risk of advanced fibrosis than those who drink less or not at all. Mechanistically, published data suggest that alcohol accelerates the progression of hepatitis C-related liver disease via increased oxidative stress, cytotoxicity, immune dysfunction and reduction of response to antiviral treatment. Similar mechanisms are believed to be in place regarding hepatitis B virus-infected subjects, although the data regarding the latter is less abundant. ${ }^{58}$

Overweight has been consistently associated with an increased risk of developing alcohol-related fibrosis and cirrhosis potentially reflecting a synergistic interaction between alcohol and lipotoxicity from steatosis as a consequence of obesity. ${ }^{59-61}$

\section{Host genetic factors}

Several observations indicate an at least partial genetic background of ALD and its progression. Persuasive evidence for a genetic background of ALD stems from a twin study undertaken in a population of 15,924 male twin pairs in which the concordance for alcohol-related cirrhosis was found three times higher in monozygotic twins than in dizygotic twins. ${ }^{62}$ Another strong genetic modifier is gender: women carry a greater risk of developing alcohol-related cirrhosis, likely attributable to hormonal effects on oxidative stress and inflammation, ${ }^{63}$ differences in expression patterns of alcohol-metabolizing enzymes, ${ }^{64}$ and a smaller distribution volume of alcohol in women and, thus, higher tissue levels of alcohol exposure. ${ }^{65}$

In the United State white Hispanic men and women reveal a higher risk for alcoholic cirrhosis compared with black and Caucasian white men and women, ${ }^{66}$ and present with alcoholrelated cirrhosis up to 10 years earlier than their Caucasian counterparts. ${ }^{67}$ However, besides constitutional differences in alcohol metabolism these differences could very well be related to cultural differences, amounts and types of alcohol consumed, dietary intake, socioeconomic status, and access to health care.

After an avalanche of relatively small candidate gene studies 
investigating hypothesis-based single nucleotide polymorphisms within genes considered relevant for ALD phenotypes generated data which could not be replicated, recent candidate gene studies and genome-wide scans have identified genetic risk factors which robustly associate with ALD and its complications. These data shed new light on yet unknown pathophysiological aspects of ALD, and potentially open the field for better prevention, screening and the development of novel therapies. The first and most robustly confirmed risk locus for ALD is a sequence variation within the gene coding for patatin-like phospholipase encoding 3 (PNPLA3, rs738409C > G, I148M) which was found to modulate the evolution of steatosis, necroinflammation, fibrosis and HCC in alcoholics. ${ }^{68,69}$ The genetic risk of ALD has also been studied on a genome-wide level by two recent studies in alcoholic cirrhosis $^{70}$ and alcoholic hepatitis. ${ }^{71}$ Both studies confirmed PNPLA3 rs738409 as a strong genetic risk locus for both alcoholic cirrhosis and $\mathrm{AH}$ with genome-wide significance, and for cirrhosis, two additional, hitherto unknown loci were identified: membrane bound 0 -acyltransferase domain containing 7 (MBOAT7) $\left(\mathrm{P}=9.25 \times 10^{-10}\right)$ and transmembrane 6 superfamily member 2 (TM6SF2). Both PNPLA3 and TM6SF2 are implicated in hepatic lipid trapping, while MBOAT7 mediates the transfer of fatty acid between phospholipids and lysophospholipids, a potent driver of hepatic inflammation. ${ }^{69}$ However, the functional implication of the mutant PNPLA3 variant is not yet fully understood, partly due to a lack of experimental translation in animals, but a homology model of the patatin domain derived from a plant protein structure suggests that the isoleucine to methionine substitution at position 148 in rs738409 is stereotypically close to the catalytic dyad of the protein (Fig. 3)..$^{72}$ This substitution likely results in impaired accessibility of PNPLA3 substrates, i.e., triglycerides, to the catalytic serine moiety, a theory supported by subsequent molecular dynamic simulations. ${ }^{73}$ This would result in a reduction in hydrolytic function, "lipid trapping" and the accumulation of fat.

\section{CLINICAL MANAGEMENT OF ALD}

\section{Diagnostic evaluation}

In most cases, ALD is a clinically silent disease with little or no symptoms in patients with early ALD and in patients with compensated cirrhosis. Thus, diagnosis depends highly on clinical suspicion, various laboratory tests and invasive or noninvasive techniques. ${ }^{74}$ In some patients with early ALD stigmata of alcohol abuse such as bilateral parotid gland hypertrophy, muscle wasting, malnutrition, Dupuytren's sign, and signs of peripheral neuropathy may be present, but more often patients are entirely asymptomatic and reluctant to openly admit that their drinking behavior may be the reason of their liver abnormalities. On physical examination of cirrhotic patients, livertypical skin signs include gynecomastia, spider angiomata, palmar erythema, and smooth tongue. Moreover, jaundice, hepatic encephalopathy, ascites and pedal edema may also be visible at first glance in patients with end-stage liver disease. The diagnosis of ALD is frequently suspected upon documentation of excess alcohol consumption (>40-50 g/day) and the presence of clinical and/or biological abnormalities suggestive of liver injury. However, on taking the medical history one needs to be aware that self-reported alcohol consumption is often under-reported and that quantification of alcohol consumption is at best semi-quantitative. ${ }^{75}$ Past complications of liver cirrhosis such as gastrointestinal bleeding, ascites, jaundice episodes, or accidents due to encephalopathy or drunkenness reported by the patient or an accompanying person are important diagnostic information.

Laboratory tests such as mean corpuscular volume of red blood cells, $\gamma$-glutamyltransferase (GGT) and aspartate aminotransferase (AST), IgA, can indicate early ALD while a decrease of albumin, increased international normalized ratio (INR), elevated bilirubin level and/or a low platelet count are signs of advanced ALD. Many heavy drinkers also reveal elevated levels

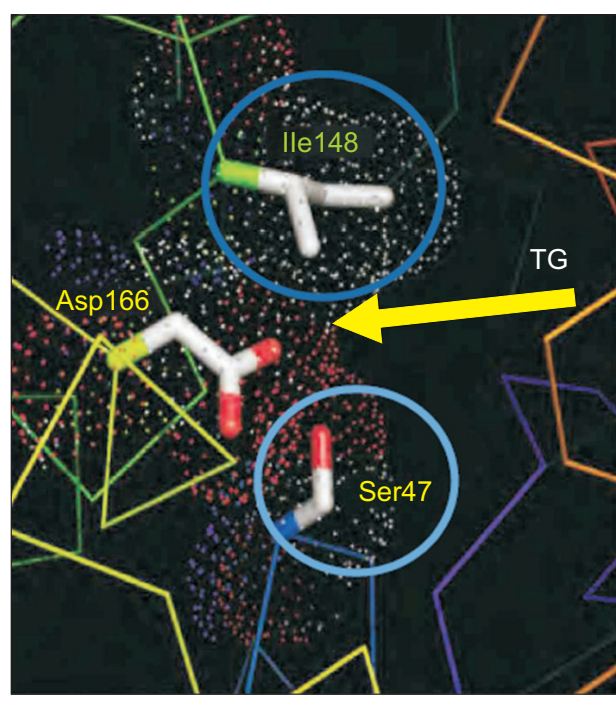

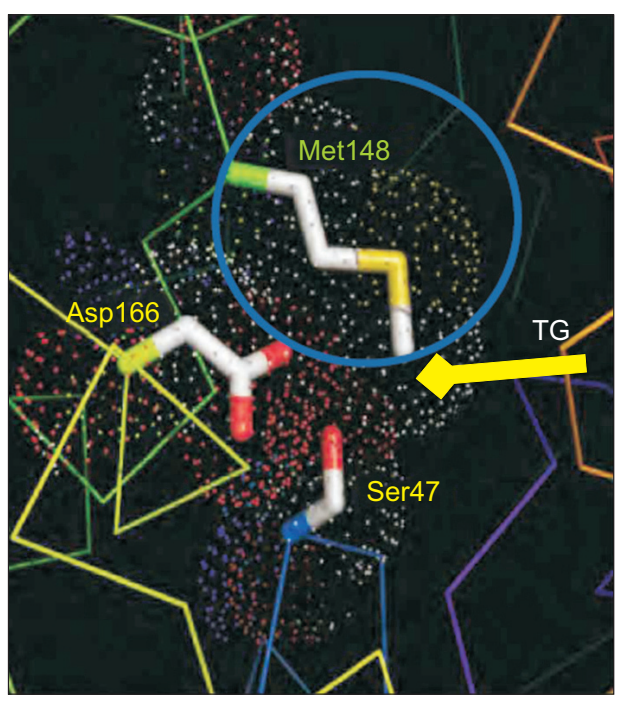

Fig. 3. Structural modifications at the PNPLA3 rs738409 locus (I148) affect the substrate binding groove rather than the catalytic center of the protein. Substituting methionine (Met) for isoleucine (Ile) at position 148 of the PNPLA3 protein reduces accessibility for substrates (e.g., triglycerides) and thus results in a loss of function. 
of triglycerides and uric acid, the latter often associated with gout attacks. ${ }^{76}$ Alcohol-specific markers include carbohydrate deficient transferrin and ethyl-glucuronide, ${ }^{77}$ however, sensitivity of the former is limited as many drinkers remain undetected due to normal levels. ${ }^{78}$ Clinically, GGT is the most frequently used marker to detect previous alcohol consumption, however, it lacks specificity and can also rise due to other etiologies. ${ }^{79}$ In patients with ALD, the AST/alanine aminotransferase (ALT) ratio typically is $>1$, and may be $>2$ in patients with $\mathrm{AH}$. However, it can also be found in patients with advanced cirrhosis regardless of the etiology.

Liver biopsy is not routinely advised in patients with early or cirrhotic stages of ALD if clinical, analytical and imaging data are undisputed. ${ }^{74,80}$ However, a liver biopsy may be useful to rule out nonalcoholic etiologies or when noninvasive tools fail to obtain a clear result. Biopsies are mostly performed percutaneously, but may require a transjugular route in patients with impaired coagulation due to a low platelet count and/or a prolonged prothrombin time, or when portal pressure shall be measured in addition. Sometimes, a liver biopsy can help to convince a patient of the cause of their liver abnormalities, and to persuade patients to change their drinking behavior, although this line of reasoning is not entirely scientific. ${ }^{81}$ A clear indication exists in patients with aggressive forms of ALD such as ASH requiring specific therapies (e.g., corticosteroids and/or pentoxifylline) and in patients with other cofactors suspected of contributing to liver disease, e.g., coexisiting viral hepatitis or iron overload. ${ }^{74}$ The typical findings in patients with ALD include steatosis, hepatocellular damage (ballooning and/or Mallory-Denk bodies), inflammatory infiltrates composed of PMN cells predominating in the lobules, and a variable degree

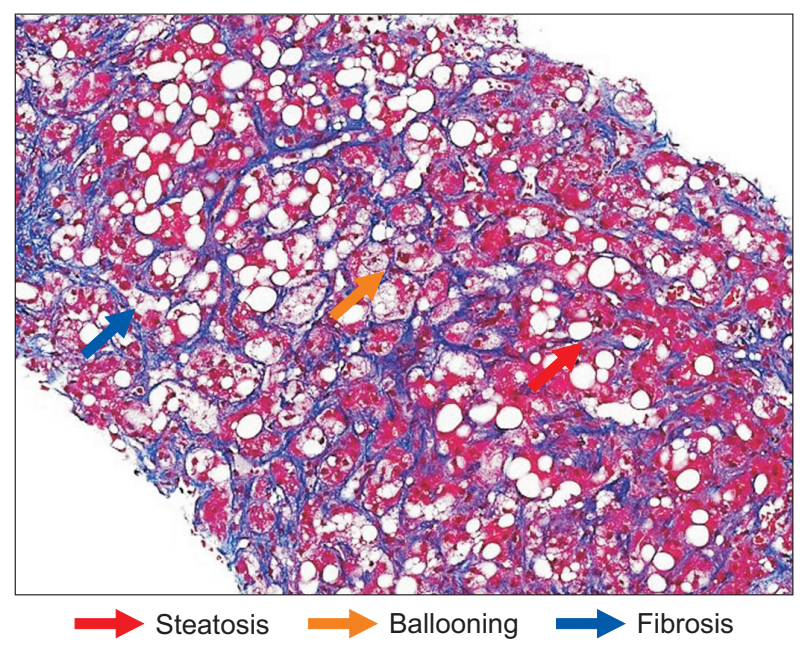

Fig. 4. Typical appearance of alcoholic cirrhosis showing three prominent features of alcoholic liver disease, i.e., fibrosis (blue arrow), steatosis (red arrow) and ballooning (yellow arrow). Significant inflammation is often not seen but consists of neutrophilic and lymphocytic infiltrates when visible (chromotrope anilin-blue stain; magnification $\times 100)$. of fibrosis and lobular distortion that may progress to cirrhosis (Fig. 4). ${ }^{82}$

For the assessment of liver fibrosis in patients with ALD, there are noninvasive methods including serum markers and liver stiffness measurement, however, none has been sufficiently validated in ALD. Simple tests that rely on AST levels, such as AST to platelet ratio index and AST/ALT ratio, are not particularly useful in ALD due to the higher AST values in such patients that do not necessarily correlate with severe fibrosis. ${ }^{83}$ Single variables such as hyaluronic acid are useful to confirm advanced fibrosis or cirrhosis, but are neither specific nor helpful in early diagnosis of ALD. Branded panels such as FibroTest, FibroMeter and Enhanced Liver Fibrosis score have not been sufficiently validated for ALD. Common to all these tests is that they are useful to distinguish between mild and severe fibrosis, but have limited value in intermediate stages of fibrosis. ${ }^{83}$

Transient elastography $\left(\right.$ Fibroscan ${ }^{\circledR}$ ) is widely established to assess fibrosis in patients with chronic liver disease and has recently been approved by the Food and Drug Adminstration (FDA). In patients with ALD, liver stiffness correlates with the stage of fibrosis, ${ }^{84}$ but elevated values need to be interpreted with caution in patients with ALD and AST serum levels $>100$ $\mathrm{U} / \mathrm{L}$ due to the possibility of falsely elevated liver stiffness as a result of inflammation-related liver congestion. Moreover, recent alcohol consumption can also increase liver stiffness, perhaps related to the vasodilatory effects of alcohol. ${ }^{85}$ Imaging techniques can also be used to assess the severity of ALD. Ultrasonography, magnetic resonance imaging (MRI), and computed tomography are useful to detect steatosis, advanced fibrosis/ cirrhosis as well as signs of portal hypertension. ${ }^{86}$ Moreover, they are useful for the screening and assessment of complications such as ascites and portal vein thrombosis. Among those methods, ultrasound is the most widely used due to its low cost. MRI and MR spectroscopy are reliable tools for quantifying steatosis but their use is limited by high cost. ${ }^{87}$ Transient elastography (Fibroscan ${ }^{\circledR}$ ) offers a software update to quantify liver fat termed Controlled Attenuation Parameter (CAP function) as a significantly cheaper alternative ${ }^{88}$ however, comparative studies are lacking.

A distinct entity represents severe ASH as a relatively rare but serious complication of ALD characterized by new onset jaundice and/or ascites in heavy drinkers with or without underlying advanced ALD. Population based studies estimate approximately 4.5 hospitalizations for AH per 100,000 persons each year, with a slight male predominance, and wide variation across countries. ${ }^{89}$ Prospective studies assessing the incidence, risk factors and clinical features of $\mathrm{AH}$ are clearly needed as it is assumed that a large proportion of ASH cases remain unrecognized and therefore not appropriately treated.

Patients with ASH typically present with rapidly progressive jaundice, often accompanied by fever, abdominal discomfort, anorexia, and weight loss. In severe cases, patients present with 
ascites, encephalopathy, hepatorenal failure and/or variceal bleeding. Patients with severe AH frequently present with the clinical picture of a so-called systemic inflammatory syndrome characterized by tachycardia, leucocytosis, and elevated C-reactive protein and procalcitonin probably due to sterile inflammation and/or or concomitant infections. ${ }^{90}$ In some patients, ASH is the first manifestation of a previously unnoticed ALD, in others it can be a complication of cirrhosis.

Serum liver enzyme levels are often elevated 2- to 6-fold, and lower that in acute viral hepatitis, characteristically with AST elevation exceeding that of ALT related to an alcohol-induced deficiency of pyridoxal 5'-phosphate (vitamin $\mathrm{B}_{6}$ ). ${ }^{91}$ Most patients with $\mathrm{AH}$ have some degree of coagulopathy with an increased INR impaired liver function, and/or low platelet numbers due to splenomegaly from portal hypertension or direct alcohol toxicity on platelets. Particularly severe is the development of kidney failure due to hepatorenal syndrome or acute tubular necrosis which identifies the subgroup with the worst prognosis. ${ }^{92}$

Of note, patients with ALD can also show an episode of jaundice and liver decompensation due to other reasons than $\mathrm{AH}$ such as in sepsis, biliary obstruction, diffuse HCC, drug-induced liver injury or gastrointestinal bleeding. Infections, particularly spontaneous bacterial peritonitis, must be ruled out as they can present with similar clinical findings (abdominal pain, fever, leukocytosis), and because they are a contraindication to specific therapy with corticosteroids. This is why a correct diagnosis and detailed work-up is so important and advocates a liver biopsy as set forth in recent clinical practice guidelines. ${ }^{74,80,93}$ Due to frequent coexisting ascites and/or coagulopathy a transjugular route is often preferred which also allows for the measurement of hepatovenous pressure gradient as a surrogate marker of portal pressure. Serologic evaluation for viral hepatitis and imaging with Doppler ultrasound to exclude biliary or vascular disorders and HCC are recommended.

Several models have been developed to help predict outcomes of patients with $\mathrm{AH}$ and to guide therapy (Table 2). The most widely used is the Maddrey et al.'s ${ }^{94}$ discriminant function (DF) introduced already in 1978, which is calculated as $4.6 \times$ (prothrombin time/patient-prothrombin time/control)+serum bilirubin. A DF value $\geq 32$ is indicative of a high risk of short-term mortality (35\% at 1 month) and selects patients for corticosteroid therapy. Additional predictive models include the Model for End-Stage Liver Disease (MELD), the Glasgow alcoholic hepatitis (GAH) score, the Age, Bilirubin, INR, Creatinine (ABIC) score. ${ }^{95-97}$ The MELD is a statistical model that is calculated using serum bilirubin, creatinine, and INR, which is able to predict 30- and 90-day mortality in patients with AH with accuracy similar to the DF. ${ }^{95,97}$ The GAH score incorporates age, serum bilirubin, blood urea nitrogen, prothrombin time, and peripheral white blood cell count, and accurately predicts short- (28 days) and midterm- (84 days) mortality. The ABIC uses age, bilirubin, INR, and creatinine to estimate a 90-day risk of mortality, and can categorize patients into low (0\%), intermediate (30\%), and high (75\%) risk of death. The MELD has been evaluated in the U.S. cohorts, the GAH in populations from the United Kingdom, and the ABIC in Spain. ${ }^{98-100}$ An important innovation was the cre-

Table 2. Scores for Assessing AH Severity

\begin{tabular}{|c|c|c|c|c|c|c|}
\hline Score & \multicolumn{4}{|c|}{ Calculator } & Interpretation & Remarks \\
\hline $\mathrm{DF}$ & \multicolumn{4}{|c|}{$\mathrm{DF}=4.6$ (patient's PT-reference PT)+total bilirubin (mg/dL) } & $\begin{array}{l}\text { Poor prognosis when } \geq 32 \text {; } \\
\text { defines threshold for } \\
\text { corticosteroid therapy }\end{array}$ & $\begin{array}{l}\text { Most widely used score in } \\
\text { clinical studies } \\
\text { No consideration of kidney } \\
\text { function }\end{array}$ \\
\hline MELD & \multicolumn{4}{|c|}{ MELD $=3.8 \times \log ^{(\text {bilirubin }[\mathrm{mg} / \mathrm{dL}])}+11.2 \times \log ^{(\mathrm{INR})}+9.6 \times \log ^{(\text {creatinine }[\mathrm{mg} / \mathrm{dL}])}+6.4$} & Poor prognosis when $\geq 18$ & $\begin{array}{l}\text { Designed for listing patients } \\
\text { for liver transplant; perfor- } \\
\text { mance comparable with DF }\end{array}$ \\
\hline ABIC & \multicolumn{4}{|c|}{ (age $\times 0.1)+($ serum bilirubin×0.08)+(serum creatinine $\times 0.3)+(I N R \times 0.8)$} & $\begin{array}{l}\text { Low risk } \mathrm{ABIC} \leq 6.71 \\
\text { Intermediate risk when } \\
\mathrm{ABIC}>6.71 \text { and } \leq 9.0 \\
\text { High risk when } \mathrm{ABIC}>9.0\end{array}$ & $\begin{array}{l}\text { Not validated outside Spain } \\
\text { Not designed to guide therapy } \\
\text { for patients with } \mathrm{AH}\end{array}$ \\
\hline \multirow[t]{6}{*}{ GAH } & & 1 & 2 & 3 & \multirow{6}{*}{$\begin{array}{l}\text { Poor prognosis if score }>8 \\
\text { (calculated on day } 1 \text { and } 7 \\
\text { of hospitalization) }\end{array}$} & \multirow{6}{*}{$\begin{array}{l}\text { Requires more variables than } \\
\text { the other scores }\end{array}$} \\
\hline & Age & $<50$ & $\geq 50$ & - & & \\
\hline & Leucocytes & $<15$ & $\geq 15$ & - & & \\
\hline & Urea $(\mathrm{mmol} / \mathrm{L})$ & $<5$ & $\geq 5$ & - & & \\
\hline & INR & $<1.5$ & $1.5-2.0$ & $>2.0$ & & \\
\hline & Bilirubin (mg/dL) & $<7.3$ & $7.4-14.6$ & $>14.6$ & & \\
\hline
\end{tabular}

AH, alcoholic hepatitis; DF, discriminant function; PT, prothrombin time; MELD, Model for End-Stage Liver Disease; INR, international normalized ratio; ABIC, Age, Bilirubin, INR, Creatinine; GAH, Glasgow alcoholic hepatitis. 
ation of the Lille model which assesses the patients' prognosis as per response to corticosteroid therapy. The Lille model measures the change in serum bilirubin after one week of corticosteroid incorporating age, albumin, creatinine, and prothrombin time. ${ }^{101}$ In those not responding to corticosteroids within 7 days of treatment clinical practice guidelines recommend cessation of corticosteroids since the risks, i.e., severe infections, with continued therapy outweigh the benefits. A large multicentric study recently developed a histological scoring system, Alcoholic Hepatitis Histological score (AHHS), capable of predicting short-term survival in $\mathrm{AH}$ patients. AHHS computes fibrosis stage, PMN infiltration, type of bilirubinostasis and presence of megamitochondria which are independently associated with patients' survival in a semiquantitative manner and allows for stratification of patients into low, intermediate, or high risk for death within 90 days. $^{102}$

\section{THERAPY OF PATIENTS WITH ALD}

\section{Achieving abstinence}

The backbone of the treatment of patients with ALD is the achievement and maintenance of alcohol abstinence since the efficacy of medical treatments for ALD is limited in those who continue to drink. As many patients with ALD display clinical criteria of AUD, a generic term covering a wide variety of drinking behaviours and their consequences often labeled as "heavy drinking," "harmful drinking," "alcohol misuse/abuse," "problem drinking" and "alcohol dependence" defined by the fourth edition of the DSM criteria (DSM-IV) ${ }^{103}$ and the 10th edition of the ICD criteria (ICD-10). ${ }^{104}$ Both systems describe drinking behavior leading to physical, psychosocial and mental disadvantages requiring therapeutic intervention. Clinical research efforts have focused on treating AUD in ALD patients and current consensus is that a combination of psychosocial interventions, pharmacological therapy and medical management seems to be the most effective management strategy for AUD patients with ALD. ${ }^{105}$ Pharmaceutical approaches to treat AUD are available, however, their safe use in patients with ALD has only been tested for a few drugs. So far, only baclofen has a published track record that confirms both efficacy and safety in several open label trials ${ }^{106,107}$ and one randomized controlled trial, ${ }^{108}$ while the FDA-approved AUD drugs disulfiram and naltrexone are contraindicated in ALD patients due to possible hepatotoxicity. Nalmefene, a $\mu$ - and $\delta$-opioid receptor antagonist and $\kappa$-opioid receptor partial-agonist, was recently approved for the treatment of AUD by the FDA, but safety data in patients with ALD is limited since patients with advanced ALD were excluded from the registrations trial. ${ }^{109}$

Assigning the appropriate treatment for each AUD category in ALD patients requires careful assessment of patients in the context of integrated concepts in which physicians, addiction specialists and psychosocial support providers jointly treat ALD patients to achieve abstinence, or at least substantial risk reduction.

\section{Nutritional support}

While patients with early ALD usually are adequately nourished, those with advanced ALD, and AH in particular, reveal significant clinical signs of malnutrition. Up to $60 \%$ of alcoholics with cirrhosis and literally all hospitalized alcoholic cirrhotics reveal some degree of malnutrition which aggravates along with the severity of ALD. ${ }^{110}$ And although alcohol provides $7.1 \mathrm{kcal} / \mathrm{g}$ of energy which is more than that of carbohydrates $(4.1 \mathrm{kcal} / \mathrm{g}$ ), patients with ALD often present with severe primary and secondary malnutrition, and particularly, protein energy malnutrition. ${ }^{110}$ Therefore, adequate nutritional support is recommended in recent guidelines. ${ }^{74,80,111}$ The causes of primary malnutrition in ALD include: (1) low dietary intake due to imbalanced diet composition or replacement of food calories by those derived from alcohol; (2) lack of appetite related to dysgeusia, esophagitis, gastritis, poor dental status; (3) lack of palatability of diets low in sodium; (4) malabsorbtion because of diarrhea, exogenous pancreatic insufficiency; and (5) complications of liver disease, e.g., ascites, hepatic encephalopathy. Besides inadequate dietary intake, heavy alcohol consumption can also lead to profound interactions with the metabolism of numerous micronutrients. Uptake and bioavailability of a wide array of water- and fatsoluble vitamins as well as trace elements are influenced by concomitant heavy alcohol and can cause clinical syndromes unrelated to ALD per se, but which should be remembered when treating patients (Table 3).

While clinical trials failed to demonstrate a benefit from parenteral nutritional therapy in ALD, numerous studies provided robust evidence for a benefit from enteral nutritional support on several surrogate markers of nutritional status such as nitrogen balance, anthropometric variables and survival. ${ }^{110}$ Several studies suggested a benefit from supplementing diets with the branched-chain amino acids valine, leucine and isoleucine to maintain adequate protein intake without worsening of hepatic encephalopathy in protein-intolerant cirrhotic patients, ${ }^{112,113}$ but a recent Cochrane analysis of 37 clinical trials not restricted to ALD found only weak evidence supporting the routine use of parenteral nutrition, enteral nutrition, or oral nutritional supplements in patients with liver disease. Benefits of nutritional therapy were limited to weak endpoints such as improved bilirubin levels and a better nitrogen balance in patients actively treated with nutrition, but not on prolongation of survival. ${ }^{114}$

From a practical point of view, current guidelines recommend a dietary intake of 1.2 to $1.5 \mathrm{~g}$ of protein $/ \mathrm{kg}$ and 35 to $30 \mathrm{kcal} / \mathrm{kg}$ body weight, frequent meals including a nighttime snack. ${ }^{74,80,111}$ Considering the numerous micronutrient deficiencies in advanced ALD, adequate supplementation thereof is also advised.

In patients with severe $\mathrm{AH}$ the prevalence of malnutrition 
Table 3. Micronutrients Affected by Heavy Alcohol Consumption and Corresponding Clinical Syndromes

\begin{tabular}{ll}
\hline Micronutrient & \multicolumn{1}{c}{ Clinical syndrome } \\
\hline Vitamin A & Night blindness, infertility \\
Thiamine & Wernicke-Korsakoff encephalopathy, cardiomyopathie (Beri-Beri) \\
Folate & Anemia, increase of cancer risk \\
Vitamin D & Osteomalacia, osteopenia \\
Vitamin E & Reduced antioxidative resistance \\
Niacine & Pellagra, neuropsychiatric symptoms \\
Pyridoxalphosphat & Anemia \\
Zink & Wound healing problems, skin problems, immunodeficiency, diarrhea \\
Magnesium & Muscle cramps, glucose intolerance \\
Selenium & Myopathy, cardiomyopathy \\
\hline
\end{tabular}

reaches 100\% and a significant correlation of malnutrition with short- and long-term survival has been demonstrated. ${ }^{115}$ While earlier randomized trials in relatively small patient numbers reported a possible benefit of vigorous nutritional support in patients with alcoholic cirrhosis and $\mathrm{AH}$, including on improved survival, ${ }^{116}$ only one recent randomized controlled trial in 136 patients with biopsy-proven $\mathrm{AH}$ studied a combination of intensive enteral nutrition via feeding tube plus methylprednisolone against conventional nutrition plus methylprednisolone (controls). ${ }^{117}$ The primary endpoint was 6-month survival, and secondary end points comprised mortality at 1 month, rates of infection, and occurrence of hepatorenal failure at 6 months. Survival in both groups was similar $(44.4 \%$ vs $52.1 \%$ in controls, $\mathrm{p}=0.406$ ), and the feeding tube was poorly tolerated. However, patients with a calorie intake of less than $21.5 \mathrm{kcal} / \mathrm{kg} /$ day were more likely to die emphasizing the need for adequate nutrition.

\section{Pharmaceutical therapy}

Despite the prominent burden of ALD on liver-related morbidity and mortality, therapies that specifically target established ALD and/or fibrosis/cirrhosis are not available and very little progress has been made in this regard over the last decades in comparison to the tremendous advances in other liver diseases. For many, the therapeutic watchword has been "just stop drinking" and interest of pharmaceutical companies and clinicians in developing and testing novel drugs to treat ALD has been low. So, numerous preparations are distributed which are at best harmless, but far from truly effective.

Longest known and widely used is an extract of Silybum marianum (milk thistle) which contains silibinin as the biologically most active compound. The premier indication for silymarin treatment is Amanita phalloides (death cup fungus) intoxication in which silymarin acts as a life-saving hepatoprotectant. ${ }^{118}$ The popularity of silymarin products among patients with chronic liver disease was promoted by a clinical trial in 170 patients with cirrhosis of various etiologies which demonstrated a significant survival benefit in those treated with silymarin. ${ }^{119}$ Another multicenter trial in 200 patients with alcoholic cirrhosis treated with $450 \mathrm{mg}$ silymarin daily did not confirm a benefit, ${ }^{120}$ and a Cochrane systematic review of 13 randomized controlled trials found not benefit from silymarin treatment. ${ }^{121}$

The same fate is shared by data on propylthiouracil, ${ }^{122}$ colchicine, ${ }^{123}$ S-Adenosyl-L-methionine (SAMe), ${ }^{124}$ and polyenylphosphatidylcholine ${ }^{125}$ which all proved no more effective than placebo in the treatment of ALD.

\section{1) Alcoholic steatohepatitis}

A somewhat different situation is that of severe ASH in which therapeutic challenges reside in the restoration of liver synthetic function as well as reducing hepatic and systemic inflammation. The linchpin of AH treatment are abstinence, corticosteroids and intensive care addressing the complications of ASH such as renal failure and sepsis.

Corticosteroids have been used in the treatment of ASH for more than 40 years. ${ }^{126}$ A meta-analysis from individual data from studies considered of high quality showed improved survival in patients with a high DF when treated with corticosteroids. ${ }^{127}$ The most studied formulation is prednisolone $40 \mathrm{mg}$ daily for 4 weeks, with or without a taper after that period. The response to prednisolone can be assessed based on the change in bilirubin after one week of therapy and quantified using the Lille score, as outlined above. ${ }^{101}$ For those with a poor response as indicated by a Lille score $\geq 0.45$, stopping therapy can be considered, as these patients are not likely to benefit from continued corticosteroids and rather incur side-effects. Based on these data, expert practice guidelines recommend the use of corticosteroids in $\mathrm{AH}$ patients with a DF $>32$, and the European guideline advises cessation thereof should response after 7 days of treatment should be insufficient according to the Lille model. $^{74,80}$

Numerous reports suggested a benefit of pentoxifylline (PTX), an orally absorbed nonselective phosphodiesterase inhibitor approved for the treatment of intermittent claudication, 
in reducing the development of the hepatorenal syndrome in patients with ASH. ${ }^{128}$ However, recent data from the Steroid or Pentoxifylline for Alcoholic Hepatitis (STOPAH) trial, a large randomized-controlled trial of treatment of patients with severe AH with prednisolone or PTX, or their combination has raised doubts over the benefit of PTX in AH patients. ${ }^{129}$ Prednisolone alone reduced the risk of 28-day mortality, but no additional benefit derived from PTX. But the trial was underpowered to analyze the subgroup of patients with hepatorenal failure which may have resulted in a failure to detect a benefit in a specific group where PTX could have been of value. Similar results came from a similar trial, which however was again underpowered for the subgroup of patients with hepatorenal syndrome. ${ }^{130}$

$\mathrm{N}$-acetylcysteine (NAC) is well-established in the treatment of fulminant hepatic failure due to paracetamol overdose, ${ }^{131}$ and improves transplant-free survival in early stage nonparacetamol acute liver failure. ${ }^{132}$ A recent randomized trial showed that the combination of NAC with prednisolone reduced 1-month mortality ( $8 \%$ vs $24 \%$ ) and the incidence of hepatorenal syndrome and infection. ${ }^{133}$ The favorable safety profile of NAC makes it a potential option, in combination with corticosteroids, for patients with severe disease.

\section{Liver transplantation}

ALD is among the most frequent indications for orthotopic liver transplantation (OLT) worldwide. ${ }^{16}$ In general, mortality and morbidity after LT in ALD patients is similar to patients with other etiologies, but the causes of death after transplantation for ALD differ from those in non-ALD recipients. ${ }^{134}$ In particular, cardiovascular causes and de novo malignancies are more frequent in the patients transplanted for ALD both of which are associated with decreased survival. ${ }^{16,135}$ The combination of cardiovascular deaths and of new onset cancers of the aerodigestive tract in patients after OLT for ALD strongly suggest a causal linkage with cigarette smoking, which is common among ALD transplanted patients. These data highlight a serious health risk for ALD patients after OLT and demonstrate the need for stringent clinical monitoring and intervention for tobacco use in the pre- and post-transplant periods.

OLT listing should be considered for patients who develop liver dysfunction corresponding to a Child-Pugh score $\geq 7$ or MELD score $\geq 10$, or clinical decompensation (ascites, variceal bleeding, or hepatic encephalopathy). ${ }^{93}$

Most transplant programs require a 6-month period of abstinence before consideration for LT, mainly for two reasons: (1) to allow for recovery of liver function which may improve to the point that OLT is no longer necessary and (2) to reduce the risk of posttransplant recidivism, although its value for predicting abstinence after OLT is poor. ${ }^{136,137}$ According the "6-month rule," patients with AH are ineligible for OLT and die if they do not respond to corticosteroids. However, posttransplant outcomes including that of abstinence seem to be good for highly selected patients with severe $\mathrm{AH}$ unresponsive to medical therapy, as demonstrated by a recent French multicenter study in nonresponders to prior corticosteroid therapy. ${ }^{138}$ Mathurin et al. ${ }^{138}$ selected 26 patients with severe $\mathrm{AH}$ with a median Lille score of 0.88 indicating a high risk of short-term death for OLT after careful pretransplant assessment. The cumulative 6-month survival rate was 77\%, a figure comparable to those for other indications. Recurrence to harmful drinking was extremely rare, likely due to the stringent selection criteria (first AH episode, support from family background, exclusion of psychiatric illnesses, other substance abuse, consensus among OLT team members, absence of violence). This indication of liver transplantation is increasingly accepted in many transplant centers including in the United State. ${ }^{139}$

After OLT, ALD patients require lifelong follow-up for prevention and management of complications, just as all other OLT patients, too. As mentioned above, cardiovascular disease, chronic kidney disease, and cancer must be kept in mind. Calcineurin inhibitor-based immunosuppression (particularly cyclosporine A) increase the risk of metabolic complications such as hypertension, diabetes, and dyslipidemia, which may contribute to the high incidence of cardiovascular disease and kidney disease in ALD patients. However, ALD is a good indication of OLT as demonstrated by data from the European Liver Transplant Registry, showing survival at 84\%, 78\%, 73\%, and 58\% after 1, 3, 5 , and 10 years, respectively, which is better than that with viral hepatitis and cryptogenic cirrhosis. ${ }^{16}$

Patients transplanted due to ALD often present with multisystemic effects of long-term ethanol abuse. ${ }^{140}$ These comorbidities include malnutrition, muscle wasting due to alcoholic myopathy, vitamin deficiencies, peripheral and central neural system abnormalities, and others. Therefore, the care of patients transplanted for ALD ideally calls for a multidisciplinary approach.

\section{CONCLUSIONS}

Although much insight has been gained in the epidemiology, pathophysiology and clinical diagnosis of ALD, the armoury of therapies is still disappointing. This lack of therapeutic options to treat AUD, ALD and related complications will only improve if more scientific, medical and societal attention is paid to this prevalent and deadly disease. A coalition among political, scientific, and industry-based stakeholders is required to make a step forward. So far, these peers devoted the topic "ALD" only the role of a fringe group when drafting their health policies, research efforts and conference programs. In essence, this attitude is a good example of a prepossession that made ALD an orphan disease in its own right. But ALD is a fully preventable disease, and more efforts should be made to use this fact as an advantage. 


\section{CONFLICTS OF INTEREST}

No potential conflict of interest relevant to this article was reported.

\section{ACKNOWLEDGEMENTS}

The present work was supported by grants from the Swiss National Funds and the Swiss Foundation for Alcohol Research (SSA) to Felix Stickel.

\section{REFERENCES}

1. Rehm J, Mathers C, Popova S, Thavorncharoensap M, Teerawattananon Y, Patra J. Global burden of disease and injury and economic cost attributable to alcohol use and alcohol-use disorders. Lancet 2009;373:2223-2233.

2. World Health Organization. European status report on alcohol and health 2010. Copenhagen: WHO Regional Office for Europe, 2010.

3. Rehm J, Shield KD, Gmel G, Rehm MX, Frick U. Modeling the impact of alcohol dependence on mortality burden and the effect of available treatment interventions in the European Union. Eur Neuropsychopharmacol 2013;23:89-97.

4. Rehm J, Samokhvalov AV, Shield KD. Global burden of alcoholic liver diseases. J Hepatol 2013;59:160-168.

5. Leon DA, McCambridge J. Liver cirrhosis mortality rates in Britain from 1950 to 2002: an analysis of routine data. Lancet 2006;367:52-56.

6. Case A, Deaton A. Rising morbidity and mortality in midlife among white non-Hispanic Americans in the 21st century. Proc Natl Acad Sci U S A 2015;112:15078-15083.

7. Yadav D, Lowenfels AB. The epidemiology of pancreatitis and pancreatic cancer. Gastroenterology 2013;144:1252-1261.

8. Popova S, Lange S, Shield K, et al. Comorbidity of fetal alcohol spectrum disorder: a systematic review and meta-analysis. Lancet 2016;387:978-987.

9. Seitz HK, Stickel F. Molecular mechanisms of alcohol-mediated carcinogenesis. Nat Rev Cancer 2007;7:599-612.

10. Fernández-Solà J. Cardiovascular risks and benefits of moderate and heavy alcohol consumption. Nat Rev Cardiol 2015;12:576587.

11. Foulds JA, Adamson SJ, Boden JM, Williman JA, Mulder RT. Depression in patients with alcohol use disorders: systematic review and meta-analysis of outcomes for independent and substanceinduced disorders. J Affect Disord 2015;185:47-59.

12. Mokdad AA, Lopez AD, Shahraz S, et al. Liver cirrhosis mortality in 187 countries between 1980 and 2010: a systematic analysis. BMC Med 2014;12:145

13. World Health Organization. Global health estimates (GEHE) 2014: YLL by age, sex and cause. Geneva: World Health Organization, 2012.
14. World Health Organization. WHO mortality database: raw data files. Geneva: World Health Organization, 2015.

15. Sheron N. Alcohol and liver disease in Europe: simple measures have the potential to prevent tens of thousands of premature deaths. J Hepatol 2016;64:957-967.

16. Burra P, Senzolo M, Adam R, et al. Liver transplantation for alcoholic liver disease in Europe: a study from the ELTR (European Liver Transplant Registry). Am J Transplant 2010;10:138-148.

17. Sheron N, Hawkey C, Gilmore I. Projections of alcohol deaths: a wake-up call. Lancet 2011;377:1297-1299.

18. Teli MR, Day CP, Burt AD, Bennett MK, James OF. Determinants of progression to cirrhosis or fibrosis in pure alcoholic fatty liver. Lancet 1995;346:987-990.

19. Stickel F. Alcoholic cirrhosis and hepatocellular carcinoma. Adv Exp Med Biol 2015;815:113-130.

20. Konishi M, Ishii H. Role of microsomal enzymes in development of alcoholic liver diseases. J Gastroenterol Hepatol 2007;22 Suppl $1: S 7-S 10$.

21. Oneta CM, Lieber CS, Li J, et al. Dynamics of cytochrome P4502E1 activity in man: induction by ethanol and disappearance during withdrawal phase. J Hepatol 2002;36:47-52.

22. Neuman MG, Malnick S, Maor Y, et al. Alcoholic liver disease: clinical and translational research. Exp Mol Pathol 2015;99:596610.

23. Gouillon Z, Lucas D, Li J, et al. Inhibition of ethanol-induced liver disease in the intragastric feeding rat model by chlormethiazole. Proc Soc Exp Biol Med 2000;224:302-308.

24. Bradford BU, Kono H, Isayama F, et al. Cytochrome P450 CYP2E1, but not nicotinamide adenine dinucleotide phosphate oxidase, is required for ethanol-induced oxidative DNA damage in rodent liver. Hepatology 2005;41:336-344.

25. Scoccianti C, Cecchini M, Anderson AS, et al. European Code against Cancer 4th Edition: alcohol drinking and cancer. Cancer Epidemiol 2015;39 Suppl 1:S67-S74.

26. Gao B, Bataller R. Alcoholic liver disease: pathogenesis and new therapeutic targets. Gastroenterology 2011;141:1572-1585.

27. Brunt EM, Neuschwander-Tetri BA, Burt AD. Fatty liver disease: alcoholic and non-alcoholic. In: Burt A, Portmann B, Ferrell L, eds. MacSween's pathology of the liver. 6th ed. Edinburgh: Churchill Livingstone, 2012:293-360.

28. Roh YS, Zhang B, Loomba R, Seki E. TLR2 and TLR9 contribute to alcohol-mediated liver injury through induction of CXCL1 and neutrophil infiltration. Am J Physiol Gastrointest Liver Physiol 2015;309:G30-G41.

29. An L, Wang X, Cederbaum AI. Cytokines in alcoholic liver disease. Arch Toxicol 2012;86:1337-1348.

30. Petrasek J, Csak T, Szabo G. Toll-like receptors in liver disease. Adv Clin Chem 2013;59:155-201

31. Lemmers A, Moreno C, Gustot T, et al. The interleukin-17 pathway is involved in human alcoholic liver disease. Hepatology 2009;49:646-657.

32. Szabo G, Petrasek J. Inflammasome activation and function in 
liver disease. Nat Rev Gastroenterol Hepatol 2015;12:387-400.

33. Schuppan D. Liver fibrosis: common mechanisms and antifibrotic therapies. Clin Res Hepatol Gastroenterol 2015;39 Suppl 1:S51S59.

34. Svegliati-Baroni G, Inagaki Y, Rincon-Sanchez AR, et al. Early response of alpha2(I) collagen to acetaldehyde in human hepatic stellate cells is TGF-beta independent. Hepatology 2005;42:343352.

35. Bataller R, Schwabe RF, Choi YH, et al. NADPH oxidase signal transduces angiotensin II in hepatic stellate cells and is critical in hepatic fibrosis. J Clin Invest 2003;112:1383-1394.

36. Elinav E, Ali M, Bruck R, et al. Competitive inhibition of leptin signaling results in amelioration of liver fibrosis through modulation of stellate cell function. Hepatology 2009;49:278-286.

37. Patsenker E, Stoll M, Millonig G, et al. Cannabinoid receptor type I modulates alcohol-induced liver fibrosis. Mol Med 2011;17:1285-1294.

38. Zamara E, Novo E, Marra F, et al. 4-Hydroxynonenal as a selective pro-fibrogenic stimulus for activated human hepatic stellate cells. J Hepatol 2004;40:60-68.

39. Fattovich G, Stroffolini T, Zagni I, Donato F. Hepatocellular carcinoma in cirrhosis: incidence and risk factors. Gastroenterology 2004;127(5 Suppl 1):S35-S50.

40. Villanueva A, Portela A, Sayols S, et al. DNA methylation-based prognosis and epidrivers in hepatocellular carcinoma. Hepatology 2015;61:1945-1956.

41. Dubuquoy L, Louvet A, Lassailly G, et al. Progenitor cell expansion and impaired hepatocyte regeneration in explanted livers from alcoholic hepatitis. Gut 2015;64:1949-1960.

42. Lanthier N, Rubbia-Brandt L, Lin-Marq N, et al. Hepatic cell proliferation plays a pivotal role in the prognosis of alcoholic hepatitis. J Hepatol 2015;63:609-621.

43. Sancho-Bru P, Altamirano J, Rodrigo-Torres D, et al. Liver progenitor cell markers correlate with liver damage and predict short-term mortality in patients with alcoholic hepatitis. Hepatology 2012;55:1931-1941.

44. Mathews S, Xu M, Wang H, Bertola A, Gao B. Animals models of gastrointestinal and liver diseases. Animal models of alcoholinduced liver disease: pathophysiology, translational relevance, and challenges. Am J Physiol Gastrointest Liver Physiol 2014;306:G819G823.

45. Mandrekar P, Bataller R, Tsukamoto H, Gao B. Alcoholic hepatitis: translational approaches to develop targeted therapies. Hepatology 2016;64:1343-1355.

46. de la M Hall P, Lieber CS, DeCarli LM, et al. Models of alcoholic liver disease in rodents: a critical evaluation. Alcohol Clin Exp Res 2001;25(5 Suppl ISBRA):254S-261S.

47. Bertola A, Mathews S, Ki SH, Wang H, Gao B. Mouse model of chronic and binge ethanol feeding (the NIAAA model). Nat Protoc 2013;8:627-637.

48. Shalem 0, Sanjana NE, Zhang F. High-throughput functional genomics using CRISPR-Cas9. Nat Rev Genet 2015;16:299-311.
49. Sørensen TI, Orholm M, Bentsen KD, Høybye G, Eghøje K, Christoffersen P. Prospective evaluation of alcohol abuse and alcoholic liver injury in men as predictors of development of cirrhosis. Lancet 1984;2:241-244.

50. Kamper-Jørgensen M, Grønbaek M, Tolstrup J, Becker U. Alcohol and cirrhosis: dose. Response or threshold effect? J Hepatol 2004;41:25-30.

51. Bellentani S, Saccoccio G, Costa G, et al. Drinking habits as cofactors of risk for alcohol induced liver damage: the Dionysos Study Group. Gut 1997;41:845-850.

52. Becker U, Grønbaek M, Johansen D, Sørensen TI. Lower risk for alcohol-induced cirrhosis in wine drinkers. Hepatology 2002;35:868-875.

53. Johansen D, Friis K, Skovenborg E, Grønbaek M. Food buying habits of people who buy wine or beer: cross sectional study. BMJ 2006;332:519-522.

54. Kennedy OJ, Roderick P, Buchanan R, Fallowfield JA, Hayes PC, Parkes J. Systematic review with meta-analysis: coffee consumption and the risk of cirrhosis. Aliment Pharmacol Ther 2016;43:562-574.

55. Dam MK, Flensborg-Madsen T, Eliasen M, Becker U, Tolstrup JS. Smoking and risk of liver cirrhosis: a population-based cohort study. Scand J Gastroenterol 2013;48:585-591.

56. Shoreibah M, Anand BS, Singal AK. Alcoholic hepatitis and concomitant hepatitis C virus infection. World J Gastroenterol 2014;20:11929-11934.

57. Monto A, Patel K, Bostrom A, et al. Risks of a range of alcohol intake on hepatitis C-related fibrosis. Hepatology 2004;39:826834.

58. Gitto S, Micco L, Conti F, Andreone P, Bernardi M. Alcohol and viral hepatitis: a mini-review. Dig Liver Dis 2009;41:67-70.

59. Naveau S, Giraud V, Borotto E, Aubert A, Capron F, Chaput JC. Excess weight risk factor for alcoholic liver disease. Hepatology 1997;25:108-111.

60. Raynard B, Balian A, Fallik D, et al. Risk factors of fibrosis in alcohol-induced liver disease. Hepatology 2002;35:635-638.

61. Hart CL, Morrison DS, Batty GD, Mitchell RJ, Davey Smith G. Effect of body mass index and alcohol consumption on liver disease: analysis of data from two prospective cohort studies. BMJ 2010;340:c1240.

62. Reed T, Page WF, Viken RJ, Christian JC. Genetic predisposition to organ-specific endpoints of alcoholism. Alcohol Clin Exp Res 1996;20:1528-1533.

63. Eagon PK. Alcoholic liver injury: influence of gender and hormones. World J Gastroenterol 2010;16:1377-1384.

64. Baraona E, Abittan CS, Dohmen K, et al. Gender differences in pharmacokinetics of alcohol. Alcohol Clin Exp Res 2001;25:502507.

65. Marshall AW, Kingstone D, Boss M, Morgan MY. Ethanol elimination in males and females: relationship to menstrual cycle and body composition. Hepatology 1983;3:701-706.

66. Stinson FS, Grant BF, Dufour MC. The critical dimension of eth- 
nicity in liver cirrhosis mortality statistics. Alcohol Clin Exp Res 2001;25:1181-1187.

67. Levy RE, Catana AM, Durbin-Johnson B, Halsted CH, Medici V. Ethnic differences in presentation and severity of alcoholic liver disease. Alcohol Clin Exp Res 2015;39:566-574.

68. Anstee QM, Daly AK, Day CP. Genetics of alcoholic liver disease. Semin Liver Dis 2015;35:361-374.

69. Stickel F, Moreno C, Hampe J, Morgan MY. The genetics of alcohol dependence and alcohol-related liver disease. J Hepatol 2017;66:195-211.

70. Buch S, Stickel F, Trépo E, et al. A genome-wide association study confirms PNPLA3 and identifies TM6SF2 and MBOAT7 as risk loci for alcohol-related cirrhosis. Nat Genet 2015;47:14431448.

71. Atkinson S, Way M, McQuillin A, Morgan M, Thursz M. A genome-wide association study identifies PNPLA3 and SLC38A4 as risk loci for alcoholic hepatitis. J Hepatol 2016;64(2 Suppl):S134.

72. He S, McPhaul C, Li JZ, et al. A sequence variation (I148M) in PNPLA3 associated with nonalcoholic fatty liver disease disrupts triglyceride hydrolysis. J Biol Chem 2010;285:6706-6715.

73. Xin YN, Zhao Y, Lin ZH, Jiang X, Xuan SY, Huang J. Molecular dynamics simulation of PNPLA3 I148M polymorphism reveals reduced substrate access to the catalytic cavity. Proteins 2013;81:406-414.

74. European Association for the Study of Liver. EASL clinical practical guidelines: management of alcoholic liver disease. J Hepatol 2012;57:399-420.

75. Stockwell T, Zhao J, Greenfield T, Li J, Livingston M, Meng Y. Estimating under- and over-reporting of drinking in national surveys of alcohol consumption: identification of consistent biases across four English-speaking countries. Addiction 2016;111:1203-1213.

76. Tu HP, Tung YC, Tsai WC, Lin GT, Ko YC, Lee SS. Alcoholrelated diseases and alcohol dependence syndrome is associated with increased gout risk: a nationwide populationbased cohort study. Joint Bone Spine. Epub 2016 May 26. https://doi.org/10.1016/j.jbspin.2016.02.024.

77. Lowe JM, McDonell MG, Leickly E, et al. Determining ethyl glucuronide cutoffs when detecting self-reported alcohol use in addiction treatment patients. Alcohol Clin Exp Res 2015;39:905910.

78. Hock B, Schwarz M, Domke I, et al. Validity of carbohydratedeficient transferrin (\%CDT), gamma-glutamyltransferase (gamma-GT) and mean corpuscular erythrocyte volume (MCV) as biomarkers for chronic alcohol abuse: a study in patients with alcohol dependence and liver disorders of non-alcoholic and alcoholic origin. Addiction 2005;100:1477-1486.

79. Alatalo P, Koivisto H, Puukka K, et al. Biomarkers of liver status in heavy drinkers, moderate drinkers and abstainers. Alcohol Alcohol 2009;44:199-203.

80. O'Shea RS, Dasarathy S, McCullough AJ; Practice Guideline Committee of the American Association for the Study of Liver
Diseases; Practice Parameters Committee of the American College of Gastroenterology. Alcoholic liver disease. Hepatology 2010;51:307-328.

81. Trabut JB, Plat A, Thepot V, et al. Influence of liver biopsy on abstinence in alcohol-dependent patients. Alcohol Alcohol 2008;43:559-563.

82. Tannapfel A, Denk H, Dienes HP, et al. Histopathological diagnosis of non-alcoholic and alcoholic fatty liver disease. Virchows Arch 2011;458:511-523.

83. Lombardi R, Buzzetti E, Roccarina D, Tsochatzis EA. Non-invasive assessment of liver fibrosis in patients with alcoholic liver disease. World J Gastroenterol 2015;21:11044-11052.

84. Mueller S, Millonig G, Sarovska L, et al. Increased liver stiffness in alcoholic liver disease: differentiating fibrosis from steatohepatitis. World J Gastroenterol 2010;16:966-972.

85. Gelsi E, Dainese R, Truchi R, et al. Effect of detoxification on liver stiffness assessed by Fibroscan ${ }^{\circledR}$ in alcoholic patients. Alcohol Clin Exp Res 2011;35:566-570.

86. Penny SM. Alcoholic liver disease. Radiol Technol 2013;84:577592.

87. d'Assignies G, Fontés G, Kauffmann C, et al. Early detection of liver steatosis by magnetic resonance imaging in rats infused with glucose and intralipid solutions and correlation to insulin levels. Metabolism 2013;62:1850-1857.

88. de Lédinghen V, Vergniol J, Capdepont M, et al. Controlled attenuation parameter (CAP) for the diagnosis of steatosis: a prospective study of 5323 examinations. J Hepatol 2014;60:1026-1031.

89. Sandahl TD, Jepsen P, Thomsen KL, Vilstrup H. Incidence and mortality of alcoholic hepatitis in Denmark 1999-2008: a nationwide population based cohort study. J Hepatol 2011;54:760-764.

90. Cervoni JP, Thévenot T, Weil D, et al. C-reactive protein predicts short-term mortality in patients with cirrhosis. J Hepatol 2012;56:1299-1304.

91. Diehl AM, Potter J, Boitnott J, Van Duyn MA, Herlong HF, Mezey E. Relationship between pyridoxal 5'-phosphate deficiency and aminotransferase levels in alcoholic hepatitis. Gastroenterology 1984;86:632-636.

92. Martín-Llahí M, Guevara M, Torre A, et al. Prognostic importance of the cause of renal failure in patients with cirrhosis. Gastroenterology 2011;140:488-496.

93. Murray KF, Carithers RL Jr; AASLD. AASLD practice guidelines: evaluation of the patient for liver transplantation. Hepatology 2005;41:1407-1432.

94. Maddrey WC, Boitnott JK, Bedine MS, Weber FL Jr, Mezey E, White RI Jr. Corticosteroid therapy of alcoholic hepatitis. Gastroenterology 1978;75:193-199.

95. Dunn W, Jamil LH, Brown LS, et al. MELD accurately predicts mortality in patients with alcoholic hepatitis. Hepatology 2005;41:353-358.

96. Forrest EH, Morris AJ, Stewart S, et al. The Glasgow alcoholic hepatitis score identifies patients who may benefit from corticosteroids. Gut 2007;56:1743-1746. 
97. Dominguez M, Rincón D, Abraldes JG, et al. A new scoring system for prognostic stratification of patients with alcoholic hepatitis. Am J Gastroenterol 2008;103:2747-2756.

98. Srikureja W, Kyulo NL, Runyon BA, Hu KQ. MELD score is a better prognostic model than Child-Turcotte-Pugh score or discriminant function score in patients with alcoholic hepatitis. J Hepatol 2005;42:700-706

99. Sandahl TD, Jepsen P, Ott P, Vilstrup H. Validation of prognostic scores for clinical use in patients with alcoholic hepatitis. Scand J Gastroenterol 2011;46:1127-1132.

100. Papastergiou V, Tsochatzis EA, Pieri G, et al. Nine scoring models for short-term mortality in alcoholic hepatitis: cross-validation in a biopsy-proven cohort. Aliment Pharmacol Ther 2014;39:721732.

101. Louvet A, Naveau S, Abdelnour M, et al. The Lille model: a new tool for therapeutic strategy in patients with severe alcoholic hepatitis treated with steroids. Hepatology 2007;45:1348-1354.

102. Altamirano J, Miquel R, Katoonizadeh A, et al. A histologic scoring system for prognosis of patients with alcoholic hepatitis. Gastroenterology 2014;146:1231-1239.

103. American Psychiatric Association. Diagnostic and statistical manual of mental disorders: DSM-IV. 4th ed. Washington, DC: American Psychiatric Association, 1994.

104. World Health Organization. The ICD-10 classification of mental and behavioural disorders: clinical descriptions and diagnostic guidelines. Geneva: World Health Organization, 1992.

105. Addolorato G, Mirijello A, Barrio P, Gual A. Treatment of alcohol use disorders in patients with alcoholic liver disease. J Hepatol 2016;65:618-630

106. Leggio L, Ferrulli A, Zambon A, et al. Baclofen promotes alcohol abstinence in alcohol dependent cirrhotic patients with hepatitis C virus (HCV) infection. Addict Behav 2012;37:561-564.

107. Barrault C, Lison H, Roudot-Thoraval F, et al. One year effectiveness of Baclofen treatment in 100 alcohol-dependent patients. J Hepatol 2015;62(Suppl 2):S758-S759.

108. Owens L, Rose A, Thompson A, Pirmohamed M, Gilmore I, Richardson P. Baclofen: maintenance of abstinence in alcohol dependent patients attending liver clinic. J Hepatol 2015;62(Suppl 2):S767.

109. Palpacuer C, Laviolle B, Boussageon R, Reymann JM, Bellissant E, Naudet F. Risks and benefits of nalmefene in the treatment of adult alcohol dependence: a systematic literature review and meta-analysis of published and unpublished double-blind randomized controlled trials. PLoS Med 2015;12:e1001924.

110. Stickel F, Hoehn B, Schuppan D, Seitz HK. Review article: nutritional therapy in alcoholic liver disease. Aliment Pharmacol Ther 2003;18:357-373.

111. Plauth M, Cabré E, Riggio 0, et al. ESPEN guidelines on enteral nutrition: liver disease. Clin Nutr 2006;25:285-294.

112. Marchesini G, Dioguardi FS, Bianchi GP, et al. Long-term oral branched-chain amino acid treatment in chronic hepatic encephalopathy: a randomized double-blind casein-controlled trial. The
Italian Multicenter Study Group. J Hepatol 1990;11:92-101.

113. Muto Y, Sato S, Watanabe A, et al. Effects of oral branched-chain amino acid granules on event-free survival in patients with liver cirrhosis. Clin Gastroenterol Hepatol 2005;3:705-713.

114. Koretz RL, Avenell A, Lipman TO. Nutritional support for liver disease. Cochrane Database Syst Rev 2012;(5):CD008344.

115. Mendenhall C, Roselle GA, Gartside P, Moritz T. Relationship of protein calorie malnutrition to alcoholic liver disease: a reexamination of data from two Veterans Administration Cooperative Studies. Alcohol Clin Exp Res 1995;19:635-641.

116. Fialla $A D$, Israelsen $M$, Hamberg 0 , Krag A, Gluud LL. Nutritional therapy in cirrhosis or alcoholic hepatitis: a systematic review and meta-analysis. Liver Int 2015;35:2072-2078.

117. Moreno C, Deltenre P, Senterre C, et al. Intensive enteral nutrition is ineffective for patients with severe alcoholic hepatitis treated with corticosteroids. Gastroenterology 2016;150:903-910.

118. Floersheim GL. Treatment of human amatoxin mushroom poisoning: myths and advances in therapy. Med Toxicol 1987;2:1-9.

119. Ferenci P, Dragosics B, Dittrich H, et al. Randomized controlled trial of silymarin treatment in patients with cirrhosis of the liver. J Hepatol 1989;9:105-113.

120. Parés A, Planas R, Torres M, et al. Effects of silymarin in alcoholic patients with cirrhosis of the liver: results of a controlled, doubleblind, randomized and multicenter trial. J Hepatol 1998;28:615621.

121. Rambaldi A, Jacobs BP, Iaquinto G, Gluud C. Milk thistle for alcoholic and/or hepatitis B or C liver diseases: a systematic cochrane hepato-biliary group review with meta-analyses of randomized clinical trials. Am J Gastroenterol 2005;100:2583-2591.

122. Rambaldi A, Gluud C. Propylthiouracil for alcoholic liver disease. Cochrane Database Syst Rev 2002;(2):CD002800.

123. Rambaldi A, Gluud C. Colchicine for alcoholic and non-alcoholic liver fibrosis and cirrhosis. Cochrane Database Syst Rev 2005;(2):CD002148.

124. Rambaldi A, Gluud C. S-adenosyl-L-methionine for alcoholic liver diseases. Cochrane Database Syst Rev 2006;(2):CD002235.

125. Lieber CS, Weiss DG, Groszmann R, Paronetto F, Schenker S; Veterans Affairs Cooperative Study 391 Group. II. Veterans Affairs Cooperative Study of polyenylphosphatidylcholine in alcoholic liver disease. Alcohol Clin Exp Res 2003;27:1765-1772.

126. Stickel F, Seitz HK. Update on the management of alcoholic steatohepatitis. J Gastrointestin Liver Dis 2013;22:189-197.

127. Mathurin P, O'Grady J, Carithers RL, et al. Corticosteroids improve short-term survival in patients with severe alcoholic hepatitis: meta-analysis of individual patient data. Gut 2011;60:255260.

128. Parker R, Armstrong MJ, Corbett C, Rowe IA, Houlihan DD. Systematic review: pentoxifylline for the treatment of severe alcoholic hepatitis. Aliment Pharmacol Ther 2013;37:845-854.

129. Thursz MR, Richardson P, Allison M, et al. Prednisolone or pentoxifylline for alcoholic hepatitis. N Engl J Med 2015;372:16191628. 
130. Mathurin P, Louvet A, Duhamel A, et al. Prednisolone with vs without pentoxifylline and survival of patients with severe alcoholic hepatitis: a randomized clinical trial. JAMA 2013;310:10331041.

131. Harrison PM, Wendon JA, Gimson AE, Alexander GJ, Williams R. Improvement by acetylcysteine of hemodynamics and oxygen transport in fulminant hepatic failure. N Engl J Med 1991;324:1852-1857.

132. Lee WM, Hynan LS, Rossaro L, et al. Intravenous N-acetylcysteine improves transplant-free survival in early stage non-acetaminophen acute liver failure. Gastroenterology 2009;137:856-864.e1.

133. Nguyen-Khac E, Thevenot T, Piquet MA, et al. Glucocorticoids plus N-acetylcysteine in severe alcoholic hepatitis. N Engl J Med 2011;365:1781-1789.

134. Singal AK, Guturu P, Hmoud B, Kuo YF, Salameh H, Wiesner RH. Evolving frequency and outcomes of liver transplantation based on etiology of liver disease. Transplantation 2013;95:755-760.
135. Singal AK, Hmoud BS, Guturu P, Kuo YF. Outcome after liver transplantation for cirrhosis due to alcohol and hepatitis C: comparison to alcoholic cirrhosis and hepatitis C cirrhosis. J Clin Gastroenterol 2013;47:727-733.

136. DiMartini A, Day N, Dew MA, et al. Alcohol consumption patterns and predictors of use following liver transplantation for alcoholic liver disease. Liver Transpl 2006;12:813-820.

137. Neuberger J. Public and professional attitudes to transplanting alcoholic patients. Liver Transpl 2007;13(11 Suppl 2):S65-S68.

138. Mathurin P, Moreno C, Samuel D, et al. Early liver transplantation for severe alcoholic hepatitis. N Engl J Med 2011;365:17901800.

139. Im GY, Kim-Schluger L, Shenoy A, et al. Early liver transplantation for severe alcoholic hepatitis in the United States: a singlecenter experience. Am J Transplant 2016;16:841-849.

140. Lucey MR. Liver transplantation for alcoholic liver disease. Nat Rev Gastroenterol Hepatol 2014;11:300-307. 